\title{
Corpo performático: uma análise discursiva sobre a mulher no contexto publicitário machista
}

\author{
Performative body: a discursive analysis about women in the sexist advertising \\ context
}

Fabiane Lemes ${ }^{1}$

Recebido em: 07/10/2019
Aprovado em: 29/11/2019
Publicado em: $19 / 12 / 2019$

RESUMO: Neste artigo, discutimos a objetificação e a subjetificação da mulher enquanto corpo do afazer doméstico pelo olhar de uma campanha publicitária. Com base na Análise do Discurso francesa, sob uma perspectiva interdisciplinar possível pela Linguística Aplicada, objetivamos analisar como a mulher foi discursivizada nessa materialidade, a qual foi criada e divulgada em 2013, nas redes sociais, e se apropriou do contexto relacionado ao futebol para fazer uma analogia entre a torcida feminina e a masculina. Cogitase verificar a partir de que perspectiva a empresa se inspira ao voltar-se para lugar social ocupado pela mulher nos dias atuais, aquela que trabalha fora e, mediante resquícios do discurso machista o qual ainda vigora, sente-se e é vista por considerável parte da sociedade enquanto responsável pelos afazeres domésticos. Apropriamo-nos dos aportes teóricos de Michel Foucault e Michel Pêcheux no intuito de analisarmos as condições de possibilidade, as regularidades enunciativas e as estratégias linguísticas das quais emergem efeitos de sentido machistas. Nossa análise nos permite afirmar que as campanhas publicitárias selecionadas corroboram o discurso machista ao refutarem a igualdade entre homens e mulheres no papel social de torcedor e ao atribuírem à mulher a responsabilidade pelos afazeres domésticos.

Palavras-chave: Gênero; Feminino; Discurso Machista.

ABSTRACT: In this article, we discuss the objectification and subjectification of women as a housework body through the look of an advertising campaign. Based on the French Discourse Analysis, in an interdisciplinary perspective enabled by Applied Linguistics, our objective is to analyze how women were discursivized in this materiality, which was created and broadcasted in 2013, in social networks, and appropriated the context related to football to make an analogy between the female and male fans. We aim to verify from which perspective the company is inspired by turning to the social place occupied by women in the present day, one that works and, through remnants of the sexist discourse that still prevails, feels and is seen by a considerable part of the society as responsible for household chores. We use the theoretical contributions of Michel Foucault and Michel Pêcheux in order to analyze the conditions of possibility, the enunciative regularities and the linguistic strategies from which sexist effects of meaning emerge. Our analysis allows us to state that the selected advertising campaigns corroborate the sexist discourse by refuting equality between men and women in the social role of supporters and assigning women responsibility for household chores.

Keywords: Gender; Female; Sexist Discourse

1. Graduada em Letras, habilitação em Língua Portuguesa e suas Literaturas. Mestre em Estudos Linguísticos pela Universidade Federal de Uberlândia. Doutoranda em Estudos Linguísticos - UFU. Pesquisadora e membro do Grupo de Pesquisa O Corpo e a Imagem no Discurso. Atualmente é professora no Colégio Nacional, unidade Ituiutaba-MG. ORCID: 0000-0002-5368-6718. E-mail: lemesfabiane.ufu@gmail.com 
LEMES, F.

\section{INTRODUÇÃO}

Em 2013, a ARIEL, marca vinculada à empresa P\&G, anunciou a campanha $E u$ torço sim, nas redes sociais ${ }^{1}$, feita a partir do gênero textual tirinha e formada por quatro peças. A propaganda atingiu bastante repercussão negativa perante os usuários da internet e foi retirada de circulação, já que dela emergia uma injunção machista que subjugava a mulher em relação ao homem. Nessa perspectiva, a princípio a mulher é retratada como torcedora de futebol e, posteriormente, é objetificada na função de dona de casa, característica que se sobrepõe, por meio dos efeitos de sentido, a qualquer outro posicionamento social ocupado por essa. Para tanto, há recursos imagéticos e linguísticos que estabelecem regularidades enunciativas, as quais denotam estereótipos acerca de um "suposto" comportamento feminino ao assistir jogos de futebol, concomitantemente a implicações de tal ato.

Propriedade da P\&G, a ARIEL é reconhecida mundialmente pelo sabão que produz destinado à lavagem de roupas. Nas prateleiras desde 1967, a marca alcançou o topo da fama em 1990, chegando aos domicílios brasileiros oito anos depois. Objetivando o marketing e a conquista do público para competir com a marca líder de vendas naquele momento, a ARIEL teve a iniciativa de valorizar a mulher mediante seu papel social dos dias atuais ao erigir o conceito: $A$ vida é muito mais do que lavar roupa. Nesse sentido, a eficiência do produto proporcionaria tempo de realizar atividades além do cuidado com as roupas, por exemplo, dedicar-se à família e trabalhar fora ${ }^{2}$.

Por conseguinte, neste trabalho, embasamo-nos epistemologicamente na Análise do Discurso francesa (AD) e na Linguística Aplicada (LA), cuja compreensão possibilita a inter-relação de teorias de origem histórica, social, cultural, antropológica e ideológica, todas atravessadas pela linguagem. Assim, intentamos analisar a apropriação e representação, feitas pela ARIEL, do lugar social ocupado pela mulher nos dias atuais, aquela que trabalha fora e, tendo em vista resquícios do discurso machista os quais ainda resvalam, sente-se e é vista, muitas vezes, por considerável parte da sociedade como responsável pelos afazeres domésticos. Logo, o objetivo da campanha publicitária condiz com o que propõe - a valorização da mulher - ou reforça o lugar de subalterno imposto à mulher social, histórica e culturamente?

\footnotetext{
1 https://www.facebook.com/descubraariel/

2 Disponível em: http://mundodasmarcas.blogspot.com.br/2006/06/ariel-pense-limpo-pense-ariel.html
} 


\section{LEMES, $\mathbf{F}$.}

A partir desse questionamento, erigimos nossa discussão retomando conceitos fundamentais para esta proposta, aliados a conjecturas inerentes ao conceito de gênero, conforme propõe Butler. Posteriormente, analisamos as imagens e os dizeres presentes nas tirinhas com o intuito de abarcar as percepções de sentido imanentes. Para tanto, ordenamos os dados por regularidades enunciativas. Por fim, explicitamos a objetificação e a subjetivação da mulher em um batimento descrição-interpretação (ORLANDI, 2015), em que perfazemos as condições de produção do corpus.

\section{Gênero e sexo: ideologia ou biologia}

De acordo Judith Butler (2003), o gênero é uma identidade erigida ao longo dos anos por meio de repetições de gestos e atitudes, o que o torna um gesto performático envolvido pelo discurso. Nessa conjuntura, os corpos e suas vivências estariam sujeitos a formas de submissão, conforme apregoa Foucault (2004), o que aponta para o processo ininterrupto de subordinação dos corpos, gestos e comportamentos, com ênfase nas práticas discursivas.

Assim sendo, não há inerência entre gênero e corpo, ou seja, não há vínculo entre ambos. Em outras palavras, o corpo não corresponde necessariamente à sua natureza, mas às relações sociais que o estabelecem. É, portanto, configurado politicamente, delineado por construções sociais nas quais se instauram o discurso. Logo, o gênero como construto que significa e se ressignifica pela memória discursiva, de forma a estabelecer e restringir os corpos mediante construções identitárias.

Para Amazonas e Rabelo (2014), não há divisão entre sexo/gênero, pois não há uma característica peculiar de sujeito, sob o ponto de vista pós-estruturalista, tendo em vista a impossibilidade de assegurar que o gênero seja, especificamente, oriundo de determinações biológicas, as quais configuram o sexo. Nesse contexto, existe uma relação binária entre biológico e cultural, e a cultura seria a responsável por estabelecer a essência do sujeito, concebida socialmente (AMAZONAS; RABELO, 2014, p. 1469).

Foucault (2004) sugere a desconstrução do imbricamento entre gênero e sexualidade, já que o gênero é da ordem social, configurando-se como representação cujo princípio refuta preceitos biológicos. Nesse hiato, o gênero categoriza o indivíduo, criando, muitas vezes, estereótipos sociais:

As concepções culturais de masculino e feminino como duas categorias complementares, mas que se excluem mutuamente, nas quais todos os 
seres humanos são classificados formam, dentro de cada cultura, um sistema de gênero, um sistema simbólico ou um sistema de significações que relaciona o sexo a conteúdos culturais de acordo com valores e hierarquias sociais. Embora os significados possam variar de uma cultura para outra, qualquer sistema de sexo-gênero está sempre intimamente interligado a fatores políticos e econômicos em cada sociedade. Sob essa ótica, a construção social do sexo em gênero e a assimetria que caracteriza todos os sistemas de gêneros através das diferentes culturas (embora cada qual de seu modo) são entendidas como sendo "sistematicamente ligadas à organização da desigualdade social (LAURETIS, 1994, p. 211-212).

Para além da representação social, a questão de gênero também almeja diferenciar masculino do feminino, e essa distinção está na "ordem das coisas" (Bourdieu, 2010). Portanto, a desigualdade social, apontada por Lauretis, impõe principalmente essa distinção entre masculino e feminino, os quais se complementam e se rejeitam mutuamente.

Ainda que nosso enfoque seja uma peça publicitária cujo conteúdo promove produtos de limpeza, percebemos a representação do feminino pelo viés sexual. No caso da primeira tirinha, esse corpo é significado como objeto de distração, o qual impede total atenção do telespectador no jogo de futebol, conforme veremos adiante.

Conforme Lauretis (1994), essa sexualização feminina foi construída historicamente mediante oposição entre masculino e feminino. O feminismo hodierno foi o precursor de concepções acerca da sexualidade feminina independentemente da masculina, alcançando legitimidade autônoma. Contudo, há um consenso que praticamente impossibilita essa desvinculação de ambos, imbricando-os de forma a torná-los praticamente inerentes.

Embora Lauretis proponha o desvencilhar entre as categorias sexo e gênero, ao mesmo tempo a autora constrói uma problematização haja vista que as,

relações sociais de gênero que constituem e validam a opressão sexual das mulheres; e, em segundo lugar, negar o gênero significa permanecer "dentro da ideologia", de uma ideologia que não coincidentemente, embora não intencionalmente, reverte em benefício do sujeito do gênero masculino (LAURETIS, 1994, p. 223).

Conforme a autora, esse rompimento depreenderia traços negativos para algumas teorias modernas cujo embasamento permanece pautado na alteridade, ou seja, apesar de almejarem a elaboração de políticas autônomas, sempre o fazem em relação ao masculino. Dessa forma, constituem-se pelo viés androcêntrico, pois a busca pela desconstrução da supremacia masculina é feita somente por oposição, impedindo a anulação concreta das tradições patriarcais.

Revista do SELL, Uberaba - V. 8 n. 2, p. 261-278, Jul./Dez. - 2019. 


\section{LEMES, F.}

Um dos principais questionamentos de Lauretis (1994) repousa justamente sobre a imperatividade de distanciamento do modelo androcêntrico que vigora socialmente. Para ela, somente assim o gênero seria pensado mediante outro ponto de vista, desconstruindo definitivamente os controles patriarcais, por meio dos quais gênero e sexualidade se constroem pelo/no "discurso da sexualidade masculina" (LAURETIS, 1994, p. 227). Em contrapartida, a autora questiona a possibilidade de sua proposição, tendo em mente que os sujeitos são formados por representações sociais fortemente cristalizadas, tornando-se quase impossível a imersão em posicionamentos distintos daqueles pré-estabelecidos.

Dentre as formas de controle oriundas do patriarcado está o discurso machista, também constituinte da sociedade em que estamos inseridos. Bourdieu (2010) argumenta que esses construtos patriarcais solidificaram-se através de um processo denominado de "trabalho de eternização". Por conseguinte, o discurso machista age em grandes proporções de forma a tornar-se dominante. Há, portanto, um paradoxo: por um lado, tem-se a dificuldade de romper as barreiras advindas de um discurso soberano desde os primórdios, por outro, tem-se um discurso cujo propósito está na visibilidade, na "simples" necessidade de ser por si, não pelo outro. Sobre isso, Lauretis (1994, p. 228) afirma: "A construção do gênero ocorre hoje através das várias tecnologias do gênero (p. ex., o cinema) e discursos institucionais (p. ex., a teoria) com poder de controlar o campo do significado social e assim produzir, promover e "implantar" representações de gênero.

Apesar da influência das tecnologias do gênero ao disseminarem o significado de gênero, junto a discursos outros, ressaltamos o lugar da mídia enquanto propagadora desses discursos, por meio de revistas, comerciais, músicas, entre outros, veiculados pela internet e televisão, o que contribui com o fortalecimento da opressão e com 0 desempoderamento da mulher, submetendo-a mais uma vez ao homem.

Para Tedeschi:

[...] a desigualdade de gênero passa a ter um caráter universal, construído e reconstruído numa teia de significados produzidos por vários discursos, como a filosofia, a religião, e educação, o direito, etc. perpetuando-se através da história e legitimando-se sob seu tempo (TEDESCHI, 2008, p. 123).

Essa desigualdade, proposta por Tedeschi (2008), permeia os gêneros masculino e feminino e é significada a partir de discursos, em que a mulher assume certa fragilidade frente ao homem. Nesse contexto, é a ela imposta uma limitação, conforme argumenta Beauvoir (1970), deslegitimando-a enquanto sujeito, integrante da sociedade, 
LEMES, F.

de forma a sugerir o "ser mulher" como condição. Em contrapartida, ser homem não é uma ocorrência estranha, pois ele "está em seu direito sendo homem" (BEAUVOIR, Ibid., p. 9). Exemplificando tais apontamentos, a autora elenca frases como: "você pensa assim porque é uma mulher". Logo, ser mulher, sob essa perspectiva, teria um caráter completamente subjetivo, o que denuncia uma ordem machista, já que transgridem o direito de equidade há algum tempo aspirado pela mulher.

A posteriori, as características biológicas da mulher são avaliadas negativamente; condições únicas que a reprimem em sua subjetividade. Ao ver a mulher dessa forma, o homem se esquece de seu referente corpóreo, porque também possui hormônios, substância que muitas vezes dita a conduta feminina. Nesse aspecto, ser homem é vantajoso por ser algo normatizado, trata-se de uma dádiva, assim vista pelo próprio homem, pois faz parte da normalidade, já que essa condição passa a ser considerada como um favorecimento pelo próprio homem, que se autodetermina em sua característica funcional. Em outras palavras, o corpo da mulher e sua condição biológica muitas vezes são considerados um impedimento, uma prisão. Dessarte, o feminino o é em relação ao masculino, jamais por si só, o que resulta na sujeição da mulher ao homem, o qual, em sua completude simbólica, não precisa de referência, pois subsiste como modelo. Assim, a mulher só existe pela alteridade, sua natureza não é essência.

Sobre a alteridade, Beauvoir (1970) explana que o desejo de se opor não partiu do objetivo de separar os sexos entre si, mas da condição do ser humano que, para ser, precisa sempre se contrapor. Por essa dependência permear o âmago da espécie humana, a autora indaga a razão dessa necessidade não ter surgido primeiramente pela distinção dos sexos, o que a leva a crer na condição subalterna da mulher:

Elas são mulheres em virtude de sua estrutura fisiológica; por mais longe que se remonte na história, sempre estiveram subordinadas ao homem: sua dependência não é consequência de um evento ou de uma evolução, ela não aconteceu. E, em parte, porque escapa ao caráter acidental do fato histórico que a alteridade aparece aqui como um absoluto (BEAUVOIR, 1970, p. 12-13).

A asserção de Beauvoir indica uma submissão que parece não ter tido uma origem específica, porque é inerente ao fato de ser mulher. Isso porque, segundo a autora, muitas mulheres não se assumem como sujeitos; contrariamente, elas se referem a si mesmas por "as mulheres", na terceira pessoa, quando, na verdade, deveriam se incluir nesse lugar com o uso de "nós mulheres", sempre em primeira pessoa. Para Beauvoir a simples terminologia incutiria à mulher a posição de sujeito, atribuindo o lugar de "outro" àqueles que não fazem parte de seu grupo, ou seja, os homens. Se assim o 
LEMES, F.

fizesse, a mulher alcançaria a autonomia, a independência, portanto, colocar-se-ia como essência.

Conforme Beauvoir, um dos grandes problemas reside na estrutura simbólica do movimento feminino. Por isso, elas receberam somente o que os homens concordaram Ihes dar, elas não adquiriram, entretanto ganharam. Sendo assim, a mulher não reivindica sua posição de sujeito inteiro, já que não possui estratégias para tanto, ou ainda não as enxergou. Ela simplesmente reconhece sua existência, a existência humana, imanente ao homem, sem reclamar a reciprocidade dele, e também se satisfaz, incontáveis vezes, no lugar do "outro".

Coadunando com a premissa de Lauretis (1994) da referente "mulher", Beauvoir (1970) arquiteta uma linha de raciocínio, no decorrer de seu texto, enfatizando o peso da carga conferida à mulher sob a ótica cultural, haja vista o fato de uma "simples" terminologia abarcar em si tantas significações, papéis e coações pré-estabelecidas. Mediante tais inferências, Beauvoir aborda as palavras "mulher" e "fêmea", relacionando-as a questões culturais e biológicas. Para a autora, enquanto aquele termo seria definido a partir do gênero, ou seja, pela autorrepresentação social, este seria qualificado por fatores biológicos. Então, esse seria o princípio que rege e condiciona os indivíduos aos moldes pré-estabelecidos pelo corpo social em que estão inseridos, de modo a sentenciá-los à condescendência perene de sua condição, coerente e imutável.

Segundo Louro (2000), ao longo dos anos "novas identidades sociais" irromperam, as quais adquiriram visibilidade em virtude de distintas organizações sociais, sendo uma delas a corrente feminista, cujo surgimento envolve amplas discussões e debates no que concerne às "identidades e as práticas sexuais e de gênero" (LOURO, Ibid., p. 7). Por conseguinte, tal processo, concretizado a partir de resistências ao que é padronizado socialmente, originou a terminologia "política de identidades", destacada pela autora.

Somado a isso, os avanços tecnológicos incutiram novas perspectivas na sociedade, gerando mudanças que suscitaram novas formas de viver e de relacionar-se. Exemplo disso são as novas práticas reprodutivas, as quais transgridem e subvertem o limiar sexual posto até então. Convém ainda ressaltar as possibilidades de transexualização, propiciada por anos de estudo, pesquisa e experiência prática, o que incide categoricamente na construção de identidades, de gênero ou sexual. Portanto, as tecnologias se tornaram integrantes da constituição identitária, são elementos influentes na pedagogização sexual devido ao seu papel nos dias atuais. 


\section{LEMES, F.}

Além disso, os aspectos culturais atravessam o ser social e são preponderantes na ordem de inscrição dos gêneros nos corpos, tornando praticamente impossível que não existam marcas culturais presentes na constituição identitária de um sujeito. De igual modo, as relações sociais implicam a expressão da sexualidade, isto é, as identidades sexuais e de gênero são erigidas por meio das relações de poder que permeiam a sociedade. Logo, as identidades sociais, independentemente se forem de gênero, classe ou raça, etc., são desenvolvidas na conjuntura histórica e cultural, originando sujeitos que se identificam com uma formação discursiva específica ao se sentirem interpelados pelo contexto.

É importante ressaltar que o sujeito se constitui por múltiplas identidades, resultando em embates, dissensões. Além do mais, ocasionalmente essas identidades distintas podem deslumbrar apenas por um breve momento, vindo a tornarem-se insignificantes posteriormente. A respeito disso, Louro (2000) pondera que as identidades sociais, geralmente, são fragmentadas, instáveis, históricas e plurais. Essa instabilidade é muito oportuna quando se trata da ascensão de determinada classe social, contudo, chega a ser inadmissível ao manifestar-se nas situações relacionadas às identidades de gênero e culturais, pois há uma imensa teimosia social em aceitar o que se considera tradicionalmente uma "transgressão dos limites".

Com o fito de conquistar mudanças nesse panorama, em que a mulher é subalterna, o que redunda no surgimento do movimento feminista, cujo cerne está na igualdade dos sexos, Beauvoir admite que o foco e o grave problema se situam na premissa da luta feminista. Segundo ela, é preciso que se refutem as ideias de "superioridade, inferioridade, igualdade que desvirtuam todas as discussões e reiniciar do começo" (BEAUVOIR, 1970, p. 21). Esse embate, com imprescindível premência de ruptura, surgiu do orgulho masculino, porque assim que as mulheres despertaram e lutaram por seus direitos e, por conseguinte, pela equidade, o homem revidou competitivamente, pois passou a ver a mulher na como uma aliada, mas como uma ameaça ao seu poderio.

Exemplo desse orgulho masculino, que perdura hoje, materializa-se por discursividades de cunho machista, consoante o corpus que elegemos para apreciação. A fim de atingir nosso objetivo de análise, valemo-nos de construtos teóricos que nos interpelam enquanto sujeitos, os quais são descritos na próxima seção.

\section{Subsídios teóricos do discurso}

Revista do SELL, Uberaba - V. 8 n. 2, p. 261-278, Jul./Dez. - 2019. 
LEMES, $\mathbf{F}$.

Em $A$ ordem do discurso, Michel Foucault (1996) afirma que qualquer discurso constitui-se enquanto discurso de ordem, isto é, de poder, alcançando certa universalidade. Para tanto, é preciso que haja uma legitimação advinda das instâncias de poder, as quais eternizam a produção de determinados "saberes" por meio de já ditos que nos constituem enquanto sujeitos pela memória discursiva.

Sendo assim, ao ser constituído pela história, o sujeito possui uma formação que se baseia em determinações exteriores a ele, é, portanto, oriundo das relações de saber e poder que permeiam a sociedade. Esses processos, denominados objetivação, possibilitam o estudo e a inferência de temas discutidos hodiernamente com base nos subsídios teóricos propostos pela $A D$, por exemplo as questões de gênero, as quais trazem à tona problemáticas que carecem de atenção, como a inferiorização da mulher em relação aos homens, possível por um discurso machista que parece ter sido perpetuado.

Dessa forma, Foucault ressalta a ideia de que ambos os processos, de subjetivação e objetivação, são intrínsecos, haja vista sua interdependência e desenvolvimento mútuo. Desse vínculo suscitam os "jogos de verdade", assim denominados por Foucault. Apesar da nomenclatura, é preciso enfatizar que tal conceito não define a verdade em si,

as regras segundo as quais, a respeito de certas coisas, aquilo que um sujeito pode dizer decorre da questão do verdadeiro e do falso. Em suma, a história crítica do pensamento não é uma história das aquisições nem das ocultações da verdade; é a história da emergência dos jogos de verdade: é a história das "veridicções" entendidas como as formas pelas quais se articulam, sobre um campo de coisas, discursos capazes de serem ditos verdadeiros ou falsos: quais foram as condições dessa emergência, o preço com o qual, de qualquer forma, ela foi paga, seus efeitos no real e a maneira pela qual, ligando um certo tipo de objeto a certas modalidades do sujeito, ela constituiu, por um tempo, uma área e determinados indivíduos, o a priori histórico de uma experiência possível (FOUCAULT, 2006, p. 235).

Logo, os "jogos de verdade" estão interligados à legitimação de certos discursos em nossa sociedade, o que the garante um valor de verdade, sendo eternizado, conforme argumenta Bourdieu (2010), e consequentemente propagado a partir das formações discursivas, como acontece com o discurso machista. Foucault, então, indaga a motivação histórica capaz de autorizar certa ideologia tornando-a universal. 


\section{LEMES, F.}

Além de nos apropriarmos dos conceitos de objetivação e subjetivação postos por Foucault, a fim de identificar e entender de que forma esses processos se dão discursivamente na materialidade de análise selecionada para este artigo, pautamo-nos ainda o conceito de enunciado (Foucault, 1996) com o fito de entender a emergência de determinados dizeres no discurso machista, bem como a imersão da mulher tomada por objeto do discurso. Construímos nossa análise pelas cadeias inter e intradiscursiva no intuito de compreender seu funcionamento no corpus que ora apresentamos.

Para Foucault, é por meio do discurso que pautas como sexualidade e política adquirem sentido e direção. Sob essa égide, a produção do discurso não é imotivada: há uma espécie de controle dessa produção. Aliado a essa logicidade, "o discurso não é simplesmente aquilo que traduz as lutas ou os sistemas de dominação, mas aquilo por que, pelo que se luta, o poder do qual nos queremos apoderar" (FOUCAULT, 1996, p. 10). Então, o discurso predominante ergue-se mediante instrumentos de controle e técnicas de exclusão, e através de dispositivos que o classificam e difundem na esfera social.

Nessa vertente, o discurso machista pode ser correlacionado a formas de organização regidas pelas relações de poder instituídas na sociedade patriarcal, portanto, o machismo é político, uma forma de governo que estabelece a soberania do homem em relação à mulher.

De acordo com Fernandes (2007), o discurso, objeto da AD, não envolve apenas questões de ordem linguística, mas sociais e ideológicas que emanam das palavras quando são pronunciadas. Por conseguinte, a linguagem é, então, aquela que materializa e revela tais lugares socioideológicos.

Segundo Foucault (1987), a estabilização de formações discursivas se dá por meio de regularidades enunciativas. Michel Pêcheux (1975-1983), ao trabalhar mais especificamente com a língua, sinaliza como essas regularidades incidem na estrutura linguística, nos jogos por ele denominados metafóricos e que resgatam essas regularidades sugeridas por Foucault.

Outrossim, com base na $A D$, uma formação discursiva é inescapavelmente atravessada pela memória discursiva, de modo que o enunciado possa ser, também, da ordem do inconsciente. Conforme Foucault:

[...] No caso em que se puder descrever, entre um certo número de enunciados, semelhante sistema de dispersão, e no caso em que entre os objetos, os tipos de enunciação, os conceitos, as escolhas temáticas, se 
LEMES, $\mathrm{F}$.

puder definir uma regularidade (uma ordem, correlação, posições e funcionamentos, transformações), diremos, por convenção, que se trata de uma formação discursiva" (FOUCAULT, 1997, p. 43).

Porquanto, se há regularidades em certos enunciados, tem-se uma formação discursiva. Essa, por sua vez, delimita o que pode e deve ser dito, corroborando o lugar social ocupado pelo sujeito, o qual é determinado historicamente. Decerto, a memória congelada é resgatada nesses discursos e consolidada. De acordo com PÊCHEUX (1995), "a memória discursiva é entendida como algo que fala sempre, antes, em outro lugar e independentemente".

Ademais, tais conceitos são fundamentais para nossa análise que abarca questões ligadas ao gênero, erigida a seguir.

\section{Eu torço sim! Roupa?}

Com o intuito de mobilizar nosso corpus, averiguar os sentidos e as significações que dele emergem, subdividimo-lo em enunciados, a partir dos quais mobilizamos nossa perspectiva de análise. Essa se dispõe com base nas estratégias linguísticas e imagéticas presentes nas tirinhas analisadas.

A partir da análise, chegamos à conclusão de que o discurso machista é oriundo de uma técnica de dominação masculina, processo histórico apontado por Pierre Bourdieu (2010). Nesse contexto, desde os tempos remotos eram impostas à mulher as tarefas consideradas "mesquinhas", não reconhecidas como trabalho. Aos homens se destinavam os afazeres notórios, públicos, bem vistos pela sociedade. Assim, sugerir serviços domésticos aos homens seria uma inversão das relações de poder, tão discutidas por Foucault (1988), portanto uma afronta a sua masculinidade, vulgo, virilidade. 
LEMES, F.

Figura 1 - Campanha "Eu torço sim" (1)

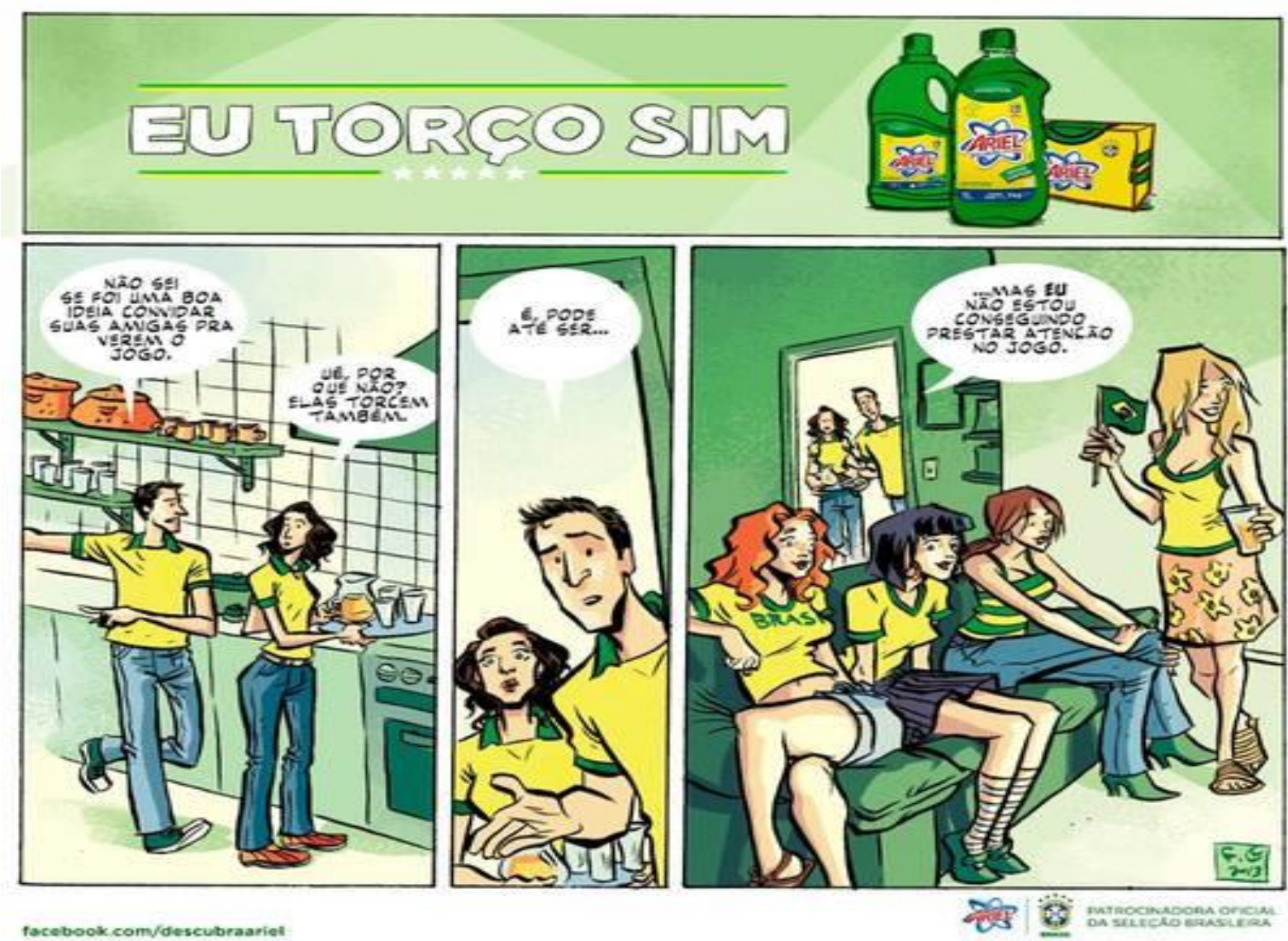

Fonte: http://carolpepita.tumblr.com/post/51595817947/ariel-não-a-pequena-sereia

$\mathrm{Na}$ tirinha acima, cônjuges dialogam na cozinha concomitantemente ao preparo de algumas bebidas, pela mulher, para as amigas que estão na sala. $O$ homem demonstra insatisfação com a presença delas, pois, segundo ele, falta-lhe atenção para assistir ao jogo. Vejamos 3 :

(E 1) Homem: Não sei se foi uma boa ideia convidar suas amigas para verem o jogo.

(E 2) Mulher: Ué, por que não? Elas torcem também.

(E 3) Homem: É, pode até ser, mas eu não estou conseguindo prestar atenção no jogo.

No E 2, acima, ao dizer que as amigas também torcem, intenta-se reivindicar o lugar da mulher no meio esportivo a partir do advérbio "também", uma vez que não há motivo para distinguir homens e mulheres enquanto torcedores, jogadores, etc.. Logo, o sujeito mulher apoia a equidade entre ambos os gêneros, almejando visibilidade num campo machista.

${ }^{3}$ Para uma melhor visualização da análise, organizamos os diálogos a partir de enunciados.

Revista do SELL, Uberaba - V. 8 n. 2, p. 261-278, Jul./Dez. - 2019. 


\section{LEMES, $\mathrm{F}$.}

Além disso, nesse mesmo enunciado, a expressão facial da mulher denota estranhamento em relação ao que o marido diz. Para ela, parece não fazer sentido seu comentário, ainda que as posições corporais, junto à expressão facial do homem, indiquem a que ele se refere.

Ao responder com a expressão "até", presente no $E$ 3, o sentido emergente é o de que ele não tem certeza se a mulher pode, de fato, torcer, o que a desqualifica nesse papel. O texto parece sugerir que as mulheres podem, nesse contexto, fazer qualquer coisa em frente à televisão, por exemplo, assistir, conversar, menos torcer porque esse lugar não lhe é legítimo.

Ao concluir o diálogo, no E 3, ao dizer que "não consegue prestar atenção no jogo", emerge o sentido de que sua atenção se volta às amigas de seu cônjuge, as quais estão na sala de estar. Questionamos o lugar do qual este homem fala, a que tipo de atenção ele se refere.

Para tentar responder a isso, observamos as vestimentas de duas das quatro mulheres, as quais deixam transparecer as pernas e parte da barriga. As demais estão com blusas mais justas, cavadas, evidenciando os seus seios. Fazemos tal observação, pois não há sinais de que elas estejam conversando, parecem bastante atentas ao jogo. Logo, não nos parece haver outra resposta que não a representação da mulher como objeto sexual, responsável pela distração do homem mediante seu momento de lazer. Nesse contexto, as roupas funcionariam como marca da denotação sexual, significadas assim na injunção do discurso machista. Outro possível significado repousa no sentido de que as mulheres não se engajam, cultural e popularmente, em certas atividades consideradas masculinas.

Tal referência da mulher enquanto objeto sexual evidencia-se ainda mais, pois é perceptível nas imagens a representação do corpo feminino perfeito no/pelo discurso mercantil. Logo, têm-se curvas acentuadas, com padrões considerados perfeitos em determinada discursividade que circula sobre beleza feminina.

Na próxima tirinha analisada, na próxima página, é perceptível que um casal está assistindo a algum jogo de futebol, até que a mulher externaliza vasto conhecimento sobre o esporte, de forma a impressionar homem. Entretanto, o desfecho do diálogo remete a uma formação discursiva machista: 


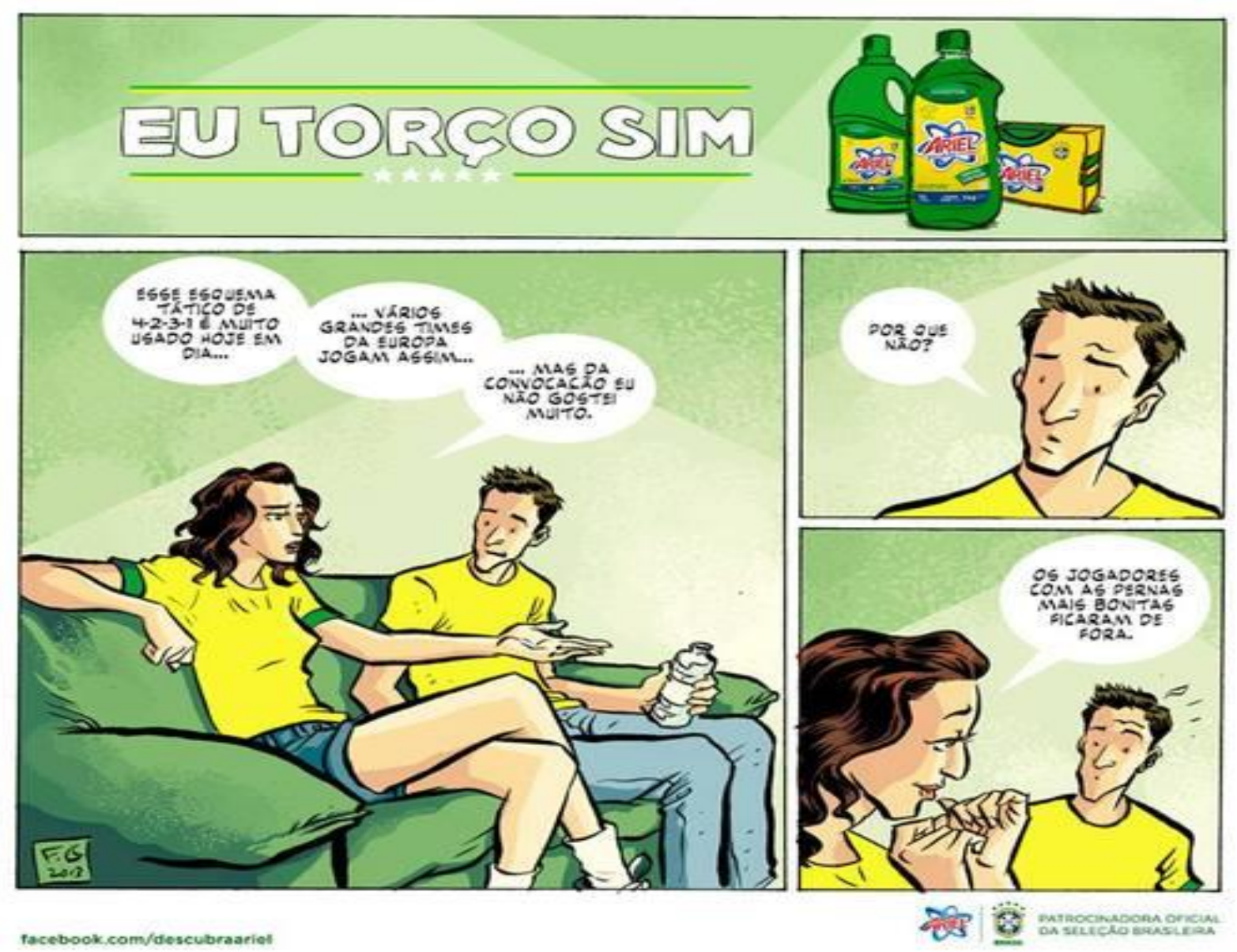

Fonte: http://carolpepita.tumblr.com/post/51595817947/ariel-não-a-pequena-sereia

(E 1) Mulher: Esse esquema tático de 4-2-3-1 é muito usado hoje em dia, vários grandes times da Europa jogam assim, mas da convocação eu não gostei muito.

(E 2) Homem: Por que não?

(E 3) Mulher: Os jogadores com as pernas mais bonitas ficaram de fora.

No $\mathrm{E} 1$, ao contextualizar os esquemas táticos que configuram os jogadores em campo, emerge o efeito de sentido o qual aponta para o fato de que a mulher pode saber tanto quanto o homem, ou mais, sobre futebol, pois ela menciona times da Europa conhecidos mundialmente como os melhores do mundo. A face da mulher demonstra seriedade e insatisfação com o que ela discutindo. Já o homem expressa espanto ao ver tanto conhecimento sobre futebol oriundo de uma mulher.

No entanto, tal efeito é desconstruído no $\mathrm{E} 3$, em que o saber é convertido em futilidade, haja vista que o contexto real de tanto conhecimento se voltaria às características físicas dos jogadores. Sintaticamente, constrói-se o sentido de que uma mulher não é capaz de falar com seriedade, pois se deixa levar por futilidades, um dos 


\section{LEMES, $\mathbf{F}$.}

determinantes considerados constitutivos do sujeito mulher, na/pela injunção do discurso machista. As imagens também contribuem para a emergência observada em nossa análise, uma vez que a mulher é representada pela expressão que denota paixão, emoção e deslumbre. O homem, por sua vez, demonstra espanto com o que está posto no $E 3$, tendo em vista que pensava se tratar de algo sério, vinculado, de fato, às técnicas de futebol.

$\mathrm{Na}$ terceira e última tirinha analisada, ao contrário das outras, não há diálogo específico entre personagens, porém quatro quadros em que as representações imagéticas são descritas pelo narrador:

Figura 3 - Campanha "Eu torço sim" (3)

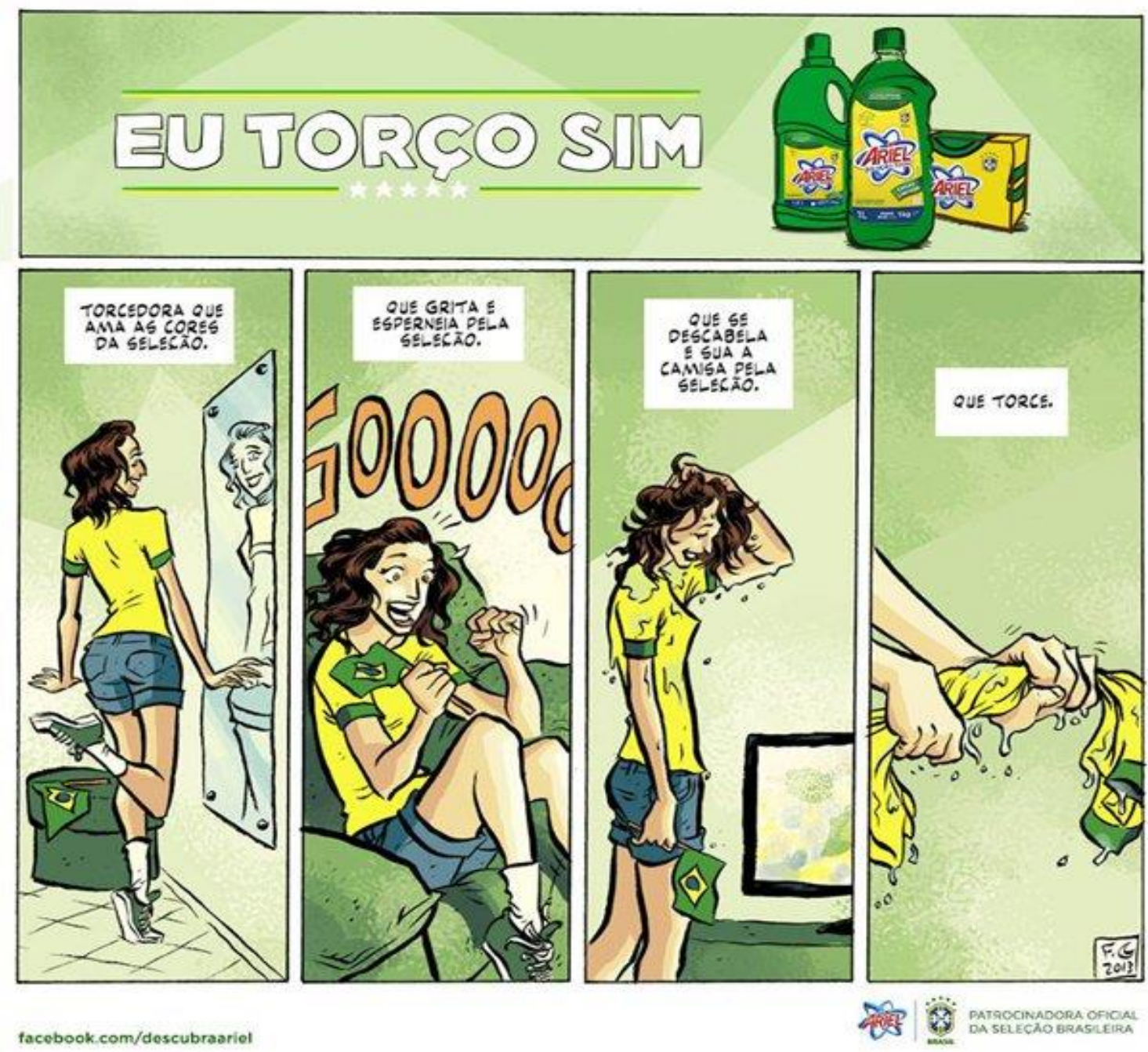

Fonte: http://carolpepita.tumblr.com/post/51595817947/ariel-não-a-pequena-sereia

(E 1) - Torcedora que ama as cores da seleção.

(E 2) - Que grita e esperneia pela seleção.

(E 3) - Que se descabela e sua a camisa pela seleção.

(E 4) - Que torce. 


\section{LEMES, $\mathrm{F}$.}

Pela imagem do primeiro quadro e também pelo E1, emerge o sentido de que a figura feminina representada se preocupa com a aparência, pois se olha no espelho. A pose e a expressão facial parecem demonstrar satisfação com o que vê. As cores amarelo e verde são difundidas como adereços da mulher.

No E 2, a imagem transmite certa empolgação pelo gol feito. Aqui, a mulher é descrita pela histeria, estratégia que a distancia da torcida masculina, deslegitima-a como torcedora.

O E 3 alude a uma situação que denota esgotamento físico. A mulher parece ter torcido tanto a ponto de se desgastar fisicamente, aparenta-se cansada, com olhos caídos, contudo ela sorri. Há menção novamente à histeria, pois o verbo descabelar se aproxima a despropósito e à inadequação.

Mais do que nas outras, a última tirinha se utiliza de recursos discursivo-visuais que idealizam uma mulher histérica, a qual se distancia, mediante satirizações e estereótipos, do modo de torcer masculino. É interessante salientar que em momento algum há referência às mulheres jogadoras de futebol profissional, esquecidas midiática e socialmente, com salários incomparavelmente menores aos dos homens. Nessa formação discursiva, a mulher parece não ter o direito nem de torcer, haja vista que esse lugar não Ihe é legítimo. Referida como histérica, seu papel no que tange ao verbo torcer, usado na campanha para aludir ao futebol, delimita-se a "torcer roupa".

\section{CONSIDERAÇÕES FINAIS}

Concluímos que dos recursos verbais e imagéticos presentes em nossa materialidade de análise emergem sentidos que desprestigiam e subjugam a mulher em relação ao homem. Isso porque ora as personagens femininas são representadas como corpo para o olhar masculino, quando as amigas da esposa tiram a atenção do homem que estava "tentando assistir ao jogo de futebol" na primeira tirinha, ora são retratadas como aquelas que não entendem de futebol, ao contrário dos homens, que parecem nascer com tal habilidade. Além disso, são colocadas como incapazes de ocupar o papel de torcedoras, haja vista que, valendo-se do humor, a última tirinha afirma que a mulher também pode torcer, vibrar durante um jogo, porém, os estigmas usados aos longo dos quadrinhos resultam numa afirmação extremamente machista: a de que, no que tange ao verbo torcer, a mulher só o pratica por torcer roupa. 


\section{LEMES, F.}

Todas essas estratégias nem sempre são postas claramente, todavia sugerem. Então, constantemente o não dito ecoa bem mais que o próprio dito, ou seja, a intenção é mitigada pela injunção, permanecendo nas entrelinhas, afinal sugere, nem sempre afirma.

Pode-se dizer que essa trama é constituída mediante o que Foucault (1987) denomina por regularidades enunciativas, as quais ecoam na estabilização dessas formações discursivas de cunho machista.

Ademais, a materialidade linguística da campanha ora analisada se pauta no contexto da mulher hodierna, que muitas vezes trabalha fora e em casa. Nessa conjuntura, as discursividades exploram o que está dado pelo viés histórico - a mulher como aquela que não pode e não deve ocupar o mesmo lugar social que o homem, pois o estereótipo de cuidadora da casa permanece intacto, como estabelecido no passado - a fim de promover produtos especificamente para o sexo feminino, desobrigando o homem de responsabilidades relacionadas à casa além daquelas de ordem financeira.

Dessarte, entendemos que, conforme assevera Foucault (1996), o sentido machista que emerge das campanhas analisadas mantém-se como discurso de ordem, cujo objetivo é restabelecer as relações de poder fundadas historicamente entre homens e mulheres. Logo, em tal injunção, ainda que a mulher tenha alcançado várias conquistas ao longo dos séculos, as quais em tese deveriam garantir-lhe equidade em relação ao homem, ela ainda é vista pela alteridade, a qual se dá por meio de um padrão social sexista.

\section{REFERÊNCIAS}

AMAZONAS, Maria Cristina Lopes de Almeida; RABELO, José Orlando Campello. A questão do método em Foucault e Butler: caminhos enredados. In: 18ํREDOR. 2014. p. 1467-1477.

BEAUVOIR, Simone de. O segundo sexo: 1 fatos e mitos. Trad. Sérgio Milliet. São Paulo: Difusão Européia. 4. Ed., 1970.

BOURDIEU, Pierre. (1930) A dominação masculina. Trad. Maria Helena Kuhner. 9. Ed. Rio de Janeiro: Bertrand Brasil, 2010.

BUTLER, Judith. Problemas de gênero: feminismo e subversão da identidade. Trad. Renato Aguiar. Rio de Janeiro: Civilização Brasileira, 2003.

FERNANDES, Cleudemar Alves. Análise do discurso: reflexões introdutórias. $2^{\underline{a}}$ ed. São Carlos: Claraluz, 2007.

FOUCAULT, Michel. A Arqueologia do saber. Trad. Luiz Felipe Baeta neves. 3. Ed. Rio de Janeiro: Forense Universitária, 1987. 


\section{LEMES, $\mathbf{F}$.}

FOUCAULT, Michel. História da Sexualidade I: a vontade de saber. Rio de Janeiro: Edições Graal, 1988.

FOUCAULT, Michel. (1970) A ordem do discurso. Aula inaugural no Collège de France, pronunciada em 1970. Trad. Laura Fraga de Almeida Sampaio. 5. Ed. São Paulo: Edições Loyola. 1996.

FOUCAULT, Michel. Resumo dos cursos do Collège de France: 1970-1982 Trad. Andrea Daher. Rio de Janeiro: J. Zahar, 1997.

FOUCAULT, Michel. Vigiar e Punir: nascimento da prisão. Trad. Raquel Ramalhete. 29. Ed. Petrópolis, RJ: Vozes, 2004.

FOUCAULT, Michel. Ética, sexualidade, política. 1926 - 1984 Manuel Barros da Motta (org.). Trad. Elisa Monteiro, Inês Autran Dourado Barbosa. 2. Ed. Rio de Janeiro: Forense Universitária, 2006.

LAURETIS, Teresa de. A tecnologia do gênero. In: HOLANDA, H. B. (org.) Tendências e Impasses - O feminismo como crítica da cultura - Rio de Janeiro: Rocco, 1994. p. 216-241.

LOURO, Guacira Lopes. Pedagogias da sexualidade. In: LOURO, Guacira Lopes (Org.). 0 corpo educado. Pedagogias da Sexualidade. Trad. Tomaz Tadeu da Silva. 2. Ed. Belo Horizonte: Autêntica, 2000.

ORLANDI, Eni Puccinelli. Análise de Discurso: Princípios e Procedimentos. 12. Ed. Campinas: Pontes, 2015.

PÊCHEUX, Michel. Semântica e Discurso: uma crítica à afirmação do óbvio. Trad. Eni P. Orlandi et al. Campinas: Ed. UNICAMP, 1995.

REIS, Daniele Fernandes. Ideias subversivas de gênero em Beauvoir e Butler. In: Sapere Aude. Vol. 4 - no 7. Belo Horizonte, 2013. p. 360-367.

TEDESCHI, Losandro Antônio. História das mulheres e as representações do feminino. 1. Ed. Curt Nimuendajú, 2008.

\section{Como citar este artigo (ABNT)}

LEMES, F. Corpo performático: uma análise discursiva sobre a mulher no contexto publicitário machista. SELL, Uberaba, MG, v. X, n. X, p. XXX-XXX, 2019. Disponível em: <inserir link de acesso>. Acesso em: inserir dia, mês e ano de acesso. DOI: inserir link do DOI.

Como citar este artigo (APA)

LEMES, F. (2019). Corpo performático: uma análise discursiva sobre a mulher no contexto publicitário machista. SELL, $X(X), X X X-X X X$. Recuperado em: inserir dia, mês e ano de acesso de inserir link de acesso. DOI: inserir link do DOI. 